\title{
APLICAÇÃO DA METODOLOGIA DE SUPERFÍCIE DE RESPOSTA NO ESTUDO DA PRODUÇÃO E EXTRAÇÃO DA POLIGALACTURONASE
}

\author{
Sharline Florentino de Melo Santos e Gorete Ribeiro de Macedo \\ Departamento de Engenharia Química, Universidade Federal do Rio Grande do Norte, Campus Universitário, Centro de Tecnologia, \\ 59072-970 Natal - RN, Brasil \\ Flávio Luiz Honorato da Silva* e Rosane Liege Alves de Souza \\ Unidade Acadêmica de Engenharia Química, Universidade Federal de Campina Grande, Centro de Tecnologia, 58109-900 Campina \\ Grande - PB, Brasil \\ Gustavo Adolfo Saavedra Pinto \\ Embrapa Agroindústria Tropical, Rua Dra. Sara Mesquita, 2270, 60511-110 Fortaleza - CE, Brasil
}

Recebido em 22/8/07; aceito em 20/6/08; publicado na web 10/11/08

\begin{abstract}
APPLICATION OF RESPONSE SURFACE METHODOLOGY TO STUDY THE PRODUCTION AND THE EXTRACTION OF POLYGALACTURONASE. The aim of this work was to verify the effects of initial medium moisture content (U), addition of ammonium sulphate $(\mathrm{N})$ and of potassium phosphate $(\mathrm{P})$ in the production of the polygalacturonase through the solid-state fermentation, using cashew apple husk as substrate and Aspergillus niger CCT0916 as transformation agent. We also studied the best extraction conditions of the produced enzyme. The best condition of production was with $\mathrm{U}$ of $40 \%, 1 \%$ of $\mathrm{N}$ and $0 \%$ of $\mathrm{P}$ being reached an activity of the poligalacturonase of $10.1 \mathrm{U} / \mathrm{g}$. The best extraction condition is an agitation system with a time of $100 \mathrm{~min}$ and a solvent-fermented medium volume ratio of $5 \mathrm{~mL} / \mathrm{g}$.
\end{abstract}

Keywords: solid-state fermentation; cashew apple; Aspergillus niger.

\section{INTRODUÇÃO}

O termo fermentação em estado sólido (FES), ou fermentação semi-sólida, ou fermentação em meio semi-sólido aplica-se aos processos onde existe crescimento de microrganismos sobre ou dentro de partículas em matriz sólida, onde a quantidade de líquido apresenta um nível de atividade de água que possa garantir o crescimento e metabolismo dos microrganismos, mas não exceda à máxima capacidade de ligação da água com a matriz sólida. ${ }^{1}$

A fermentação em estado sólido apresenta diversas vantagens em relação à fermentação submersa, principalmente quando os agentes de transformação são fungos filamentosos. Uma delas é que as condições de cultivo são mais parecidas com o habitat natural dos fungos filamentosos, com isto os fungos estão mais adaptados para crescer e excretar maior quantidade de enzimas. ${ }^{2} \mathrm{~A}$ concentração dos produtos após extração é bem maior que os obtidos no processo de fermentação submersa e gera menos resíduo líquido. Este processo desperta maior interesse econômico em regiões com abundância em biomassa e resíduos agroindustriais, que representam material barato e abundante. ${ }^{3}$

A produção de pedúnculos de caju no Brasil é estimada em torno de 1,8 milhão de t/ano, concentrando-se basicamente na região Nordeste, e com aproveitamento industrial de apenas $15 \%$ do total. ${ }^{4} \mathrm{~A}$ quantidade desperdiçada apresenta elevada concentração de nutrientes que têm potencial de uso para conversão por microrganismos, na obtenção de produtos de alto valor agregado como enzimas.

As enzimas pectinolítica ou pectinases formam um grupo heterogêneo de enzimas (pectina esterase, poligalacturonase, polimetilgalacturonase, polimetilgalacturonato liase e poligalacturonato liase) que hidrolisam as substâncias pécticas. ${ }^{5}$ Podem ser produzidas, em diferentes combinações, por plantas e por microrganismos, como

*e-mail: flhs@deq.ufcg.edu.br fungos, leveduras e bactérias. ${ }^{6}$ As pectinases microbianas respondem por $25 \%$ das vendas de enzimas para alimentos. ${ }^{5}$ São muito utilizadas nas indústrias de sucos de frutas para reduzir viscosidade e melhorar e aumentar a eficiência de filtração e de clarificação; no tratamento preliminar da uva em indústrias vinícola; para melhorar a extração de óleos vegetais e no tratamento e degomagem de fibras naturais para indústria têxtil e de papel. ${ }^{7}$

A poligalacturonase é a enzima com função hidrolítica principal. Para a maioria dos usos industriais, as poligalacturonases produzidas por fungo provam ser úteis pela alta atividade e atividade ótima em faixa de $\mathrm{pH}$ baixo, servindo para grande parte das aplicações em processos envolvendo frutas e vegetais. ${ }^{8}$

A maior parte dos microrganismos pectinolíticos produz um complexo de enzimas pectinolíticas. Fungos são geralmente usados como fonte das preparações comerciais. Aspergillus e Rhizopus são freqüentemente usados pela alta atividade pectinolítica exibida nos extratos produzidos. ${ }^{9}$

A produção de pectinases por microrganismos é influenciada pelas condições de cultivo, em particular do meio de cultura, tipo e concentração da fonte de carbono, $\mathrm{pH}$ e temperatura do cultivo, além de outros fatores. ${ }^{10} \mathrm{O}$ nível de umidade do substrato é um dos fatores que mais influenciam o processo e varia de acordo com a natureza do substrato, tipo de produto final e necessidade do microrganismo. Um nível de umidade muito alto resulta numa diminuição da porosidade, baixa difusão de oxigênio, aumento no risco de contaminação, redução no volume de gás e redução de troca gasosa. Baixos níveis de umidade levam a um crescimento baixo em relação ao ótimo e baixo grau de substrato realmente utilizado. ${ }^{11}$

Os microrganismos necessitam de carbono, nitrogênio, minerais, água, eventualmente fatores de crescimento, e caso seja aeróbio, oxigênio, para formar biomassa e impulsionar reações de biossíntese e manutenção celular. ${ }^{12} \mathrm{O}$ nitrogênio corresponde, em média, a 8-14\% do peso seco de uma bactéria ou fungo; uma grande variedade de 
compostos nitrogenados orgânicos e inorgânicos é utilizada para suprir as necessidades desse elemento durante a biossíntese. A amônia representa a forma inorgânica de nitrogênio mais assimilável pelos microrganismos. O fósforo é utilizado nas reações biossintéticas e também pode ser polimerizado para manter um nível de fosfato celular e promover o crescimento da célula. ${ }^{13}$

Um aspecto importante na fermentação em estado sólido é a recuperação adequada dos metabólitos produzidos. A eficiência de extração é um fator crítico que determina a viabilidade econômica da FES para produção de enzima. Temperatura e tipo de solvente são conhecidos como importantes parâmetros na extração de solutos de sólidos. Adicionalmente, ao lidar com enzimas, é necessário levar em conta a estabilidade térmica da enzima, que é função do tempo de exposição. ${ }^{3}$

O objetivo deste trabalho foi utilizar a metodologia do planejamento experimental fatorial e análise de superfície de resposta para verifica a influência da umidade inicial, adição de sulfato de amônia e de fosfato de potássio no estudo da produção da poligalacturonase através da fermentação em estado sólido, usando como substrato o pedúnculo de caju seco e como agente da fermentação o microrganismo Aspergillus niger CCT 0916. Também visou estudar a melhor condição de extração da enzima produzida do meio de fermentação.

\section{PARTE EXPERIMENTAL}

\section{Microrganismo}

O microrganismo empregado foi o Aspergillus niger CCT 0916, cedido pela Embrapa Agroindústria Tropical, Fortaleza-CE. Os esporos da linhagem foram preservados em tubos de ensaio com tampas rosqueadas contento solo estéril e estocados a $-18^{\circ} \mathrm{C}$.

$\mathrm{O}$ microrganismo foi ativado em duas etapas de transferência, usando um meio básico composto por pectina cítrica (10 g/L), $\mathrm{NaNO}_{3}(3 \mathrm{~g} / \mathrm{L}), \mathrm{KH}_{2} \mathrm{PO}_{4}(1 \mathrm{~g} / \mathrm{L}), \mathrm{MgSO}_{4}(0,5 \mathrm{~g} / \mathrm{L}), \mathrm{KCl}(0,5 \mathrm{~g} / \mathrm{L})$, $\mathrm{FeSO}_{4} 7 \mathrm{H}_{2} \mathrm{O}(0,01 \mathrm{~g} / \mathrm{L})$ e agar-agar $(20 \mathrm{~g} / \mathrm{L})$. $\mathrm{O}$ meio foi esterilizado por 20 min a $0,5 \mathrm{~atm} .{ }^{14}$

Os esporos foram transferidos dos tubos com solo para o meio e incubados por 5 dias em estufa a $30^{\circ} \mathrm{C}$, constituindo o primeiro repique. $\mathrm{O}$ segundo repique foi obtido de modo semelhante ao primeiro, partindo dos esporos de primeiro repique. Os esporos de segundo repique foram utilizados para obtenção de grande quantidade de esporos no meio de sabugo de milho. Cada repique pode ser mantido sob refrigeração por um período de 4 meses. Segundo este procedimento, cada tubo de ensaio contendo o microrganismo no solo só deve ser usado 4 ou 5 vezes e descartado. ${ }^{15}$

No frasco de sabugo com esporos foi adicionada uma solução $0,3 \% \mathrm{v} / \mathrm{v}$ de Tween 80 . Após agitação vigorosa, os esporos foram transferidos para erlenmeyer com auxílio de gaze estéril. A quantificação da suspensão obtida foi feita através de contagem dos esporos em Câmara de Neubauer espelhada. O volume de suspensão de esporos adicionado ao meio de fermentação foi ajustado de modo a ter-se um inóculo de $10^{7}$ esporos por g de substrato sólido.

\section{Meio de cultivo}

Como meio de cultivo foi utilizado o resíduo do pedúnculo de caju. O resíduo foi cedido por uma empresa de suco de fruta de Fortaleza-CE, que o enviou para a Embrapa Agroindústria Tropical. Ao chegar à Embrapa, o bagaço foi lavado com água, cinco vezes, na proporção $1 \mathrm{~kg}$ de bagaço para $2 \mathrm{~L}$ de água e seco em estufa com circulação de ar a $50{ }^{\circ} \mathrm{C}$ por $24 \mathrm{~h}$.

O resíduo seco foi triturado em moinho de facas e armazenado em recipiente fechado à temperatura ambiente.
As análises químicas indicam que o resíduo do pedúnculo de caju lavado e seco possui $10,2 \%$ de umidade, $0,86 \%$ de cinzas, $12,94 \%$ de proteína, 0,21\% de açúcares redutores (AR), 13,41\% de pectina e $\mathrm{pH} 4,5{ }^{16}$

\section{Estudo da produção da poligalacturonase}

No estudo das condições de produção da poligalacturonase verificou-se a influência das variáveis concentração inicial de umidade $(\mathrm{U})$, suplementação com uma fonte de nitrogênio $(\mathrm{N})$ e suplementação com uma fonte de fósforo $(\mathrm{P})$, através de um planejamento experimental fatorial $2^{3}$, com 3 repetições no ponto central, como mostra a Tabela 1. Como variável de resposta foi avaliada a atividade da poligalacturonase.

Os níveis das variáveis independentes utilizadas em ordem crescente $(-1,0,+1)$ foram 40,50 e $60 \%$ para umidade inicial (U); $0 ; 0,5$ e $1,0 \%$ para nitrogênio $(\mathrm{N})$ e $0,0,3$ e $0,6 \%$ para fósforo $(\mathrm{P})$. Como fonte de nitrogênio foi utilizado o sulfato de amônia PA e como fonte de fósforo, o fosfato de potássio monobásico PA.

A umidade inicial do meio foi ajustada de acordo com a Equação 1 , que indica o volume de água a ser adicionado em $10 \mathrm{~g}$ de resíduo para se obter a umidade desejada.

\section{Volume água adicionado $(\mathrm{mL})=0,3528 \times$ (umidade desejada) $-8,1578(1)$}

As fermentações foram realizadas em erlenmeyer de $250 \mathrm{~mL}$ contendo $20 \mathrm{~g}$ do meio. Para garantir a uniformidade das amostragens o meio foi preparado, de acordo com a matriz do planejamento mostrado na Tabela 1 , em becker de polipropileno e então distribuído nos erlenmeyers. Os frascos foram tampados com tampão de algodão envolvido com gaze e autoclavados a $0,5 \mathrm{~atm}$ por $5 \mathrm{~min}$.

Ao meio de fermentação frio foram inoculados $10^{7}$ esporos $/ g$ de resíduo e incubados a $30^{\circ} \mathrm{C}$ em estufa úmida. As amostras foram retiradas em períodos de tempo regular durante o processo para a extração do complexo enzimático e posterior realização das medidas de atividade. Para cada amostragem um erlenmeyer era retirado da estufa, estando todos nas mesmas condições iniciais do processo.

A extração do complexo enzimático foi realizada adicionandose $2,5 \mathrm{~mL} / \mathrm{g}$ de meio fermentado de tampão acetato $200 \mathrm{mM} \mathrm{pH}$ 4,5. Após homogeneização, as amostras foram deixadas por $1 \mathrm{~h} \mathrm{em}$ banho-maria a $30^{\circ} \mathrm{C}$ e depois foram filtradas. $\mathrm{O}$ filtrado foi estocado em freezer.

\section{Estudo das condições de extração da enzima}

No estudo das condições de extração da enzima do meio fermentado foi feito um planejamento experimental $2^{2}$ mais configuração estrela, com 3 repetições no ponto central.

As variáveis de entrada foram o tempo de contato (t) e a razão volume solvente/g de meio fermentado (RZ). Como variável de resposta usou-se a atividade da poligalacturonase, como mostra a Tabela 4.

As extrações foram realizadas em temperatura ambiente, utilizado como solvente solução tampão acetato de sódio pH 4,5 que, segundo Castilho et al., ${ }^{3}$ tem melhores resultados que água destilada e glicerol a 50\%. Foram testados dois sistemas: um agitado e outro sem agitação. A agitação foi feita colocando-se o erlenmeyer em mesa agitada com rotação de $200 \mathrm{rpm}$.

Neste caso, foi utilizado como meio o resíduo do pedúnculo de caju com umidade inicial de $40 \%$ e sem adição de sais. O meio úmido foi distribuído em erlenmeyer de $250 \mathrm{~mL}$ ( $20 \mathrm{~g}$ ), sendo um erlenmeyer para cada condição de extração testada, e autoclavados a 0,5 atm por $5 \mathrm{~min}$. Ao meio de fermentação frio foram inoculados $10^{7}$ esporos $/ \mathrm{g}$ 
de resíduo e incubados a $30^{\circ} \mathrm{C}$ em estufa úmida por $16 \mathrm{~h}$.

Após extração seguindo a matriz do planejamento, Tabela 4, os extratos foram filtrados e estocados em freezer para posterior análise enzimática.

\section{Atividade da poligalacturonase}

A atividade poligalacturonásica do extrato enzimático foi baseada no aumento dos grupos redutores formados por ação da enzima. Em tubos de ensaio contendo $4 \mathrm{~mL}$ de solução de ácido poligalacturônico $0,25 \%$ p/v preparada em tampão acetato $200 \mathrm{mM}$, pH 4,5, previamente aclimatado a $35^{\circ} \mathrm{C}$, adicionou-se $0,25 \mathrm{~mL}$ de extrato enzimático, prosseguindo a reação enzimática por $30 \mathrm{~min}$ a $35^{\circ} \mathrm{C}$. Terminada a reação, transferiu-se $0,25 \mathrm{~mL}$ da mistura reacional para tubos de ensaio contendo $1 \mathrm{~mL}$ do reagente de DNS; após homogeneização adicionouse $0,75 \mathrm{~mL}$ de água destilada e segui-se o procedimento para análise dos grupos redutores pelo método do DNS.

Os ensaios foram feitos em duplicata, nos ensaios em branco (também em duplicata), a enzima foi adicionada ao ácido poligalacturônico e imediatamente transferida para os tubos contendo o DNS. A curva padrão foi obtida com solução de ácido galacturônico na faixa de 0 a $1 \mathrm{mg} / \mathrm{mL}$.

Uma unidade de atividade corresponde à quantidade de enzima que libera $1 \mu$ mol de ácido galacturônico por min de reação, nas condições de reação. Os resultados foram expressos em unidades de atividade por g de meio úmido fermentado $(\mathrm{U} / \mathrm{g})$.

\section{Análise estatística do delineamento experimental}

O nível de significância para os estudos da produção da poligalacturonase e para o estudo das condições de extração da enzima foi de $95 \%$ de confiança. Para validação dos modelos foi utilizada a análise de variância, verificando-se o coeficiente de determinação $\left(\mathrm{R}^{2}\right)$ e teste $\mathrm{F}$.

\section{RESULTADOS E DISCUSSÃO}

\section{Estudo da produção da poligalacturonase}

Utilizando a ferramenta do planejamento experimental e análise de superfície de resposta é possível investigar a influência das variáveis em um processo e a forma de interação entre estas variáveis, bem como obter o valor das variáveis que otimizem os resultados.

A Tabela 1 mostra os resultados experimentais da atividade poligalacturonásica quando se variam os fatores percentual inicial de umidade (U), adição de uma fonte de nitrogênio $(\mathrm{N})$ e adição de uma fonte de fósforo $(\mathrm{P})$. Os resultados estão apresentados para cada hora do processo analisado.

Com os resultados experimentais obtidos para cada hora de fermentação, a partir do planejamento fatorial, é possível ajustar os dados para obter equações de primeira ordem, que relacionem a atividade enzimática com os parâmetros estudados. Estas equações foram obtidas a partir das regressões lineares dos dados experimentais, utilizando o software Statistica versão 5.0. As equações obtidas para a atividade da poligalacturonase (PG) estão apresentadas na Tabela 2, junto com os coeficientes de determinação $\left(R^{2}\right)$ e os valores da razão de F. Os parâmetros em negrito são os estatisticamente significativos em nível de $95 \%$ de confiança.

$\mathrm{O}$ coeficiente de determinação $\mathrm{R}^{2}$ quantifica a qualidade do ajustamento, pois fornece uma medida da proporção da variação explicada pela equação de regressão em relação à variação total das respostas. Varia de 0 a $100 \% .{ }^{17}$

Tabela 1. Matriz do planejamento experimental e resultado experimental para o estudo da produção da poligalacturonase

\begin{tabular}{|c|c|c|c|c|c|c|c|c|c|}
\hline \multirow[b]{2}{*}{ EXP } & \multirow[b]{2}{*}{$\mathrm{U}$} & \multirow[b]{2}{*}{$\mathrm{N}$} & \multirow[b]{2}{*}{$\mathrm{P}$} & \multicolumn{6}{|c|}{ Atividade PG por horas de fermentação (U/g) } \\
\hline & & & & 7 & 22 & 30 & 46 & 54 & 70 \\
\hline 1 & $-1(40)$ & $-1(0)$ & $-1(0)$ & 9,3 & 6,2 & 6,2 & 7,0 & 3,9 & 1,8 \\
\hline 2 & $+1(60)$ & $-1(0)$ & $-1(0)$ & 0,0 & 0,1 & 1,2 & 1,2 & 0,5 & 0,0 \\
\hline 3 & $-1(40)$ & $+1(1)$ & $-1(0)$ & 3,7 & 10,1 & 10,0 & 4,2 & 3,6 & 4,4 \\
\hline 4 & $+1(60)$ & $+1(1)$ & $-1(0)$ & 0,0 & 0,0 & 0,0 & 0,2 & 0,0 & 0,5 \\
\hline 5 & $-1(40)$ & $-1(0)$ & $+1(0,6)$ & 2,9 & 6,6 & 6,8 & 4,0 & 3,7 & 2,8 \\
\hline 6 & $+1(60)$ & $-1(0)$ & $+1(0,6)$ & 0,7 & 10,4 & 0,6 & 2,5 & 0,6 & 0,4 \\
\hline 7 & $-1(40)$ & $+1(1)$ & $+1(0,6)$ & 1,6 & 0,1 & 7,2 & 7,0 & 6,4 & 4,8 \\
\hline 8 & $+1(60)$ & $+1(1)$ & $+1(0,6)$ & 0,2 & 0,8 & 0,0 & 0,0 & 1,3 & 0,5 \\
\hline 9 & $0(50)$ & $0(0,5)$ & $0(0,3)$ & 0,5 & 3,2 & 2,0 & 2,1 & 2,6 & 2,1 \\
\hline 10 & $0(50)$ & $0(0,5)$ & $0(0,3)$ & 1,1 & 3,0 & 3,5 & 2,0 & 3,2 & 2,0 \\
\hline 11 & $0(50)$ & $0(0,5)$ & $0(0,3)$ & 0,9 & 2,9 & 1,3 & 1,3 & 0,7 & 0,9 \\
\hline
\end{tabular}

$\mathrm{U}=$ percentual de umidade inicial do meio, $\mathrm{N}=$ percentual de sulfato de amônia adicionado ao meio e $\mathrm{P}=$ percentual de fosfato de potássio adicionado ao meio.

Tabela 2. Equações de primeira ordem obtidas para a atividade poligalacturonásica (PG) por hora de fermentação para o resíduo de pedúnculo de caju lavado

\begin{tabular}{|c|c|c|}
\hline Modelo atividade da poligalacturonase & $\mathrm{R}^{2}$ & $\mathrm{~F}$ \\
\hline $\mathrm{PG}(7 \mathrm{~h})=1,90-2,08 \mathrm{U}-0,93 \mathrm{~N}-0,96 \mathrm{P}+0,81 \mathrm{UN}+1,18 \mathrm{UP}+0,48 \mathrm{NP}-0,61 \mathrm{UNP}$ & 93,4 & 0,7 \\
\hline $\mathrm{PG}(22 \mathrm{~h})=3,94-1,47 \mathrm{U}-1,54 \mathrm{~N}+0,19 \mathrm{P}-0,88 \mathrm{UN}+2,60 \mathrm{UP}-2,49 \mathrm{NP}+0,10 \mathrm{UNP}$ & 97,7 & 2,0 \\
\hline $\mathrm{PG}(30 \mathrm{~h})=3,52-3,55 \mathrm{U}+0,30 \mathrm{~N}-0,35 \mathrm{P}-0,75 \mathrm{UN}+0,20 \mathrm{UP}-0,35 \mathrm{NP}+0,50 \mathrm{UNP}$ & 92,3 & 0,6 \\
\hline $\mathrm{PG}(46 \mathrm{~h})=2,86-2,29 \mathrm{U}-0,41 \mathrm{~N}+0,12 \mathrm{P}-0,46 \mathrm{UN}+0,16 \mathrm{UP}+0,53 \mathrm{NP}-0,91 \mathrm{UNP}$ & 91,5 & 0,5 \\
\hline $\mathrm{PG}(54 \mathrm{~h})=2,41-1,90 \mathrm{U}+0,33 \mathrm{~N}+0,51 \mathrm{P}-0,28 \mathrm{UN}-0,15 \mathrm{UP}+0,52 \mathrm{NP}-0,22 \mathrm{UNP}$ & 90,9 & 0,5 \\
\hline $\mathrm{PG}(70 \mathrm{~h})=1,93-1,54 \mathrm{U}+0,66 \mathrm{~N}+0,23 \mathrm{P}-0,51 \mathrm{UN}-0,13 \mathrm{UP}-0,13 \mathrm{NP}+0,03 \mathrm{UNP}$ & 99,8 & 8,5 \\
\hline
\end{tabular}


$\mathrm{O}$ teste $\mathrm{F}$ apresenta a razão entre o $\mathrm{F}$ calculado e o $\mathrm{F}$ tabelado. Sempre que esta relação for maior que 1 , a regressão é estatisticamente significativa, havendo relação entre as variáveis independentes e dependentes. Para que uma regressão seja não apenas estatisticamente significativa, mas também útil para fins preditivos, o valor da razão deve ser no mínimo maior que $4 .{ }^{18}$

As equações empíricas, com \% de confiança de 95, mostram razoáveis coeficientes de determinação, estando todos acima de $90 \%$. Com relação ao teste $\mathrm{F}$, observa-se que a razão do $\mathrm{F}$ calculado pelo F tabelado só apresenta valores estatisticamente significativos para as equações de PG (22 h) e PG (70 h), pois a razão está acima de 1, apresentando evidência estatística suficiente de uma relação linear entre as variáveis dependente $(\mathrm{PG})$ e independentes $(\mathrm{U}$ e N $) .^{18}$

Pelas equações obtidas percebe-se que a umidade é a variável que tem maior influência no processo, e que os menores valores de umidade correspondem quase sempre aos maiores valores de atividade encontrados.

De acordo com a Tabela 1 os maiores valores de atividade da poligalacturonase foram às $22 \mathrm{~h}$ de fermentação. A partir desta observação, será feito o estudo estatístico para obter uma equação que seja significativa e preditiva, o que permite identificar e quantificar o efeito das variáveis para o processo. É importante lembrar que as equações aqui apresentadas são empíricas e só devem ser aplicadas dentro da faixa dos valores estudados.

Para $22 \mathrm{~h}$ de fermentação, a equação para a atividade da poligalacturonase apresenta um $\mathrm{F}$ de 2,0 que indica um modelo significativo, mas não preditivo. Usando o diagrama de Pareto, Figura 1, é possível identificar que os efeitos do fósforo e da interação das três variáveis não são significativos, então a retirada destes parâmetros pode melhorar a qualidade do ajuste.

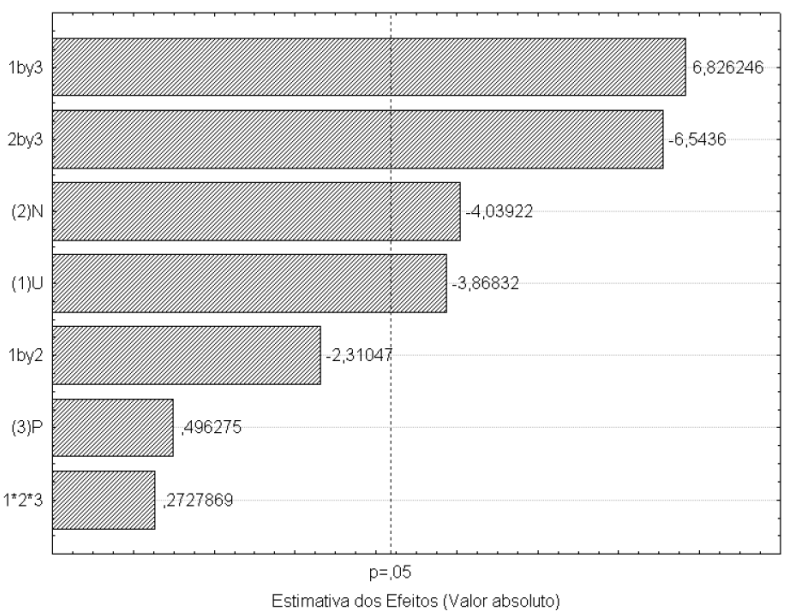

Figura 1. Diagrama de Pareto para atividade da poligalacturonase com 22 $h$ de fermentação

Com a retirada destes coeficientes, os efeitos da umidade inicial e da adição da fonte de nitrogênio passam a ser significativos, a nova equação é PG(22h)= 3,94-1,47U-1,54N-0,88UN+2,60UP-2,49NP. A Tabela 3 apresenta a análise de variância para esta equação; percebe-se que o coeficiente de explicação quase não se alterou passando de 97,7 para 97,4, mas que o valor de $\mathrm{F}$ passou de 2,0 para 7,5 e conclui-se que a equação agora é significativa e preditiva.

De acordo com a Figura 1, os efeitos de maior significância estatística são as interações da umidade com a adição da fonte de fósforo e a interação das fontes de nitrogênio e fósforo.

Para interação de umidade e fósforo, a maior atividade de PG é atingida quando ambas estão em seus níveis máximo ou mínimo. Já a interação de nitrogênio e fósforo mostra que a máxima atividade
Tabela 3. Análise de variância para atividade da poligalacturonase com 22 h de fermentação

\begin{tabular}{lcccc}
\hline Fonte variação & SQ & GL & MQ & Teste F \\
\hline Regressão & 146,22 & 5 & 29,24 & 38,05 \\
Resíduo & 3,84 & 5 & 0,77 & \\
F.ajuste & 3,80 & 3 & & \\
Erro puro & 0,05 & 2 & & \\
Total & 149,69 & 10 & & \\
\%R & 0,97 & & & \\
F tabelado $=$ & 5,05 & & F5\%= & 7,50 \\
\hline
\end{tabular}

de PG é atingida quando apenas uma das fontes está presente no meio. Assim, para umidade de $60 \%$ a maior atividade é atingida para fósforo de 0,6\% (9,98 U/g) sem adição de nitrogênio; ou com $40 \%$ de umidade, $1 \%$ de nitrogênio sem adição de fósforo $(9,84 \mathrm{U} / \mathrm{g})$.

A Figura 2 mostra a superfície de resposta construída com base neste modelo para umidade fixa em $40 \%$. Vê-se que o maior valor de atividade da poligalacturonase é obtido com a adição de $1 \%$ de sulfato de amônia $(9,84 \mathrm{U} / \mathrm{g})$. A atividade da poligalacturonase cai bastante quando os dois sais estão presentes no meio, sendo esta a condição menos favorável à produção da poligalacturonase.

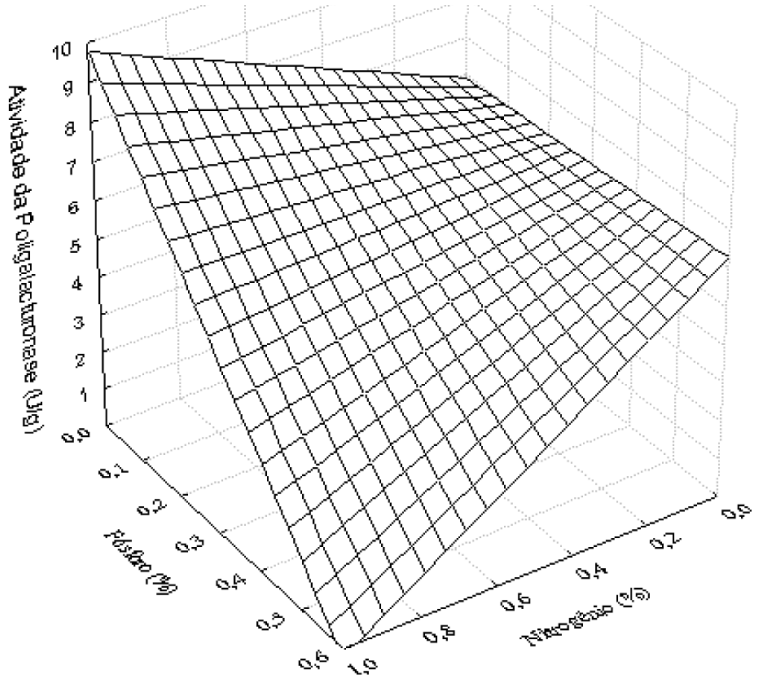

Figura 2. Influência da adição de nitrogênio e fósforo na atividade da poligalacturonase para umidade fixa em $40 \%$

\section{Estudo das condições de extração da enzima}

A Tabela 4 apresenta os resultados de atividade poligalacturonásica nas condições de extração testadas.

A análise estatística dos dados, pela metodologia do planejamento fatorial, mostrou não haver diferença significativa das variáveis de entrada, nos níveis estudados, sobre o processo em estudo, apresentando coeficientes de correlação (R) muito baixos de 0,4 sem agitação e 0,6 com agitação. Isto impossibilita a construção de modelos probabilísticos e a obtenção das superfícies de resposta, mas não inviabiliza o estudo pontual dos experimentos.

Os experimentos 5, 6 e 7 com valores de 10,6; 13,1 e 12 U/g no sistema com agitação e 9; 9,4 e 9,7 U/g sem agitação mostram a reprodutibilidade dos dados usando o ponto central. Apresentam valores de atividade PG com média de 11,9 (U/g) e desvio padrão de 1,2 no sistema com agitação e média de 9,4 (U/g) e desvio padrão de 0,3 no sistema sem agitação

$\mathrm{Na}$ Figura 3 é possível ver que o sistema que apresentou os me- 
Tabela 4. Variação da atividade poligalacturonásica em função das condições de extração

\begin{tabular}{lcccc}
\hline \multirow{2}{*}{ Exp. } & \multirow{2}{*}{$(\mathrm{min})$} & $\mathrm{RZ}(\mathrm{mL} / \mathrm{g})$ & \multicolumn{2}{c}{ Atividade PG (U/g) } \\
& $-1(30)$ & $-1(2,5)$ & 7,2 & 4,3 \\
\hline 1 & $+1(90)$ & $-1(2,5)$ & 6,8 & 5,5 \\
2 & $-1(30)$ & $+1(7,5)$ & 5,5 & 5,3 \\
3 & $+1(90)$ & $+1(7,5)$ & 9,1 & 5,7 \\
4 & $0(60)$ & $0(5)$ & 10,6 & 9,0 \\
5 & $0(60)$ & $0(5)$ & 13,1 & 9,4 \\
6 & $0(60)$ & $0(5)$ & 12,0 & 9,7 \\
7 & $+\alpha(100)$ & $0(5)$ & 16,1 & 12,4 \\
8 & $-\alpha(20)$ & $0(5)$ & 8,2 & 9,7 \\
9 & $0(60)$ & $+\alpha(8,5)$ & 12,2 & 11,1 \\
10 & $0(60)$ & $-\alpha(1,5)$ & 6,7 & 5,3 \\
11 &
\end{tabular}

$\mathrm{t}=$ tempo de contato solvente/meio fermentado, $\mathrm{RZ}=$ razão volume de solvente/g de meio fermentado.

lhores resultados de atividade foi o sistema com agitação. A melhor condição de extração é obtida no experimento 8 , com o tempo de contato entre solvente e meio de fermentação de $100 \mathrm{~min}$ e com a razão volume de solvente meio fermentado $5(\mathrm{~mL} / \mathrm{g})$, sendo a atividade da poligalacturonase de $16,1 \mathrm{U} / \mathrm{g}$. Em relação ao resultado mais baixo de atividade $4,3 \mathrm{U} / \mathrm{g}$, no sistema sem agitação com 30 min de contato e 2,5 de razão solvente/meio, experimento 1 , houve um ganho em atividade de 4 vezes.

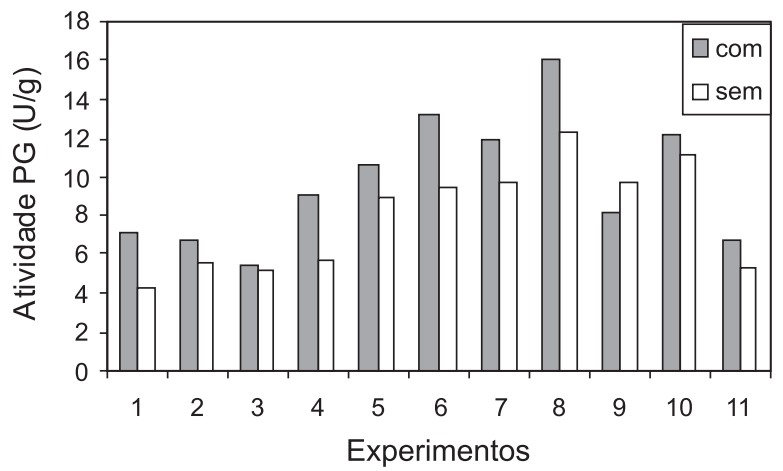

Figura 3. Efeito das condições de extração na atividade poligalacturonásica $(P G)$ nos sistemas com e sem agitação

A Figura 4 apresenta o efeito da razão solvente (tampão acetato) massa de meio fermentado na extração da poligalacturonase, com o tempo de contato fixo em $60 \mathrm{~min}$. Nela percebe-se que para razões entre 1,5 e 5 o aumento da razão possibilita uma maior extração da enzima, mas que na faixa entre 5-8,5 não há variação significativa, principalmente no sistema com agitação.

A Figura 5 mostra o efeito do tempo de contato entre solvente e meio de fermentação na atividade poligalacturonásica com a razão (RZ) fixa em $5 \mathrm{~mL} / \mathrm{g}$. Nela percebe-se que quanto maior o tempo maior a extração da poligalacturonase. Para o sistema sem agitação não há variação significativa para tempos de contato de 20-60 min.

Castilho $^{19}$ estudando a influência do tempo de contato na extração da poligalacturonase em sistema agitado por agitador mecânico encontrou um perfil parabólico no comportamento dos extratos enzimáticos obtidos entre 10 e $50 \mathrm{~min}$. O crescimento da curva de 10-30 min indica que o período de 10 min é insuficiente para a total solubilização das enzimas presentes no sólido fermentado. O decréscimo decorrido após 30 min foi atribuído à perda de atividade enzimática decorrente de fatores como maior extração de agentes desnaturantes, aumento

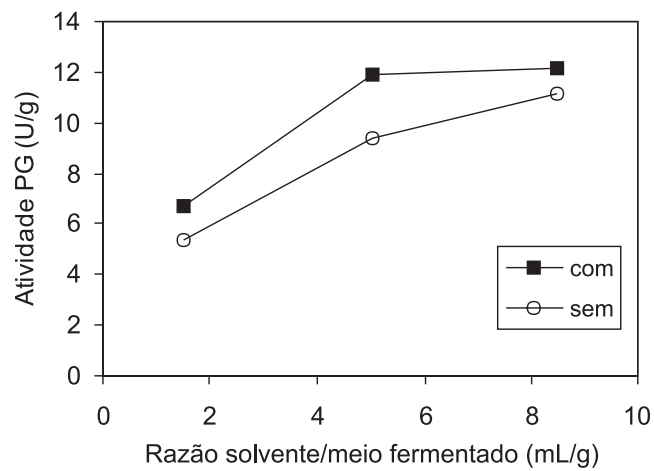

Figura 4. Efeito da razão solvente meio fermentado na extração da poligalacturonase nos sistemas com e sem agitação

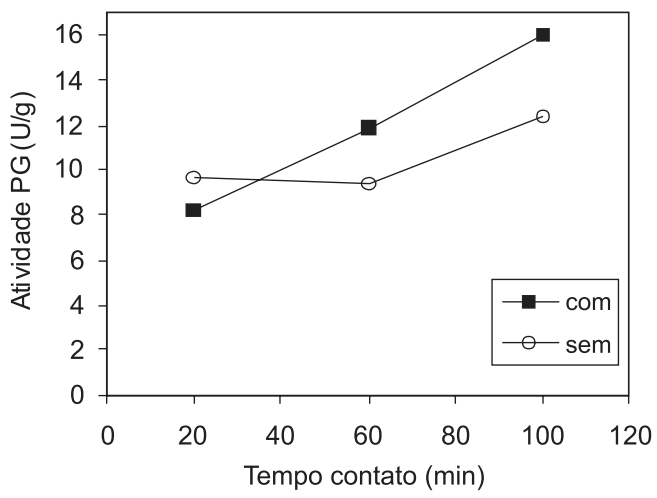

Figura 5. Efeito do tempo de contato solvente meio fermentado na extração da poligalacturonase nos sistemas com e sem agitação

da formação de espuma e adsorção de enzima às partículas sólidas mais finas. No caso aqui estudado, a agitação foi realizada em mesa agitadora não ocorrendo formação de espuma.

Na literatura encontram-se valores de atividade da poligalacturonase de $12 \mathrm{U} / g$ para bagaço de laranja, com 6 dias de fermentação, $12 \mathrm{U} / \mathrm{g}$ para casca de manga com 4 dias de fermentação e 7,5 U/g para casca de banana com 6 dias, usando o Penicillium viridicatum RFC3 ${ }^{20}$ Pinto $^{21}$ usando casca de maracujá obteve $21,85 \mathrm{U} / \mathrm{g}$ em $24 \mathrm{~h}$ com Aspergillus niger CNPAT 001. Zheng e Shetty ${ }^{8}$ após 40 dias obteve atividades de 29,4 e 20,1 U/g usando resíduos de morango e maçã, respectivamente, fermentados por Lentinus edodes. Comparando estes valores da literatura com o presente trabalho, pode-se verificar que o bagaço de caju seco é uma fonte promissora de poligalacturonase.

\section{AGRADECIMENTOS}

À CAPES e Embrapa Agroindústria Tropical (projeto 02.03.1.17) pelo auxílio financeiro.

\section{REFERÊNCIAS}

1. Pinto, G. A. S.; Brito, E. S.; Silva, F. L. H.; Santos, S. F. M.; Macedo, G. R.; Rev. Quím. Ind. 2006, 74, 18.

2. Pandey, A.; Benjamin, S.; Soccol, C. R.; Nigam, P.; Curr. Sci. 1999, 77,149 .

3. Castilho, L. R.; Medronho, R. A.; Alves, T. L. M.; Bioresour. Technol. 2000, 71,45 .

4. Kiss, J.; Revista Globo Rural. 2005, 233, 58.

5. Jayani, R. S.; Saxena, S.; Gupta, R.; Process Biochem. 2005, 40, 2931. 
6. da Silva, E. G.; Borges, M. F.; Medina, C.; Piccoli, R. H.; Schwan, R. F.; FEMS Yeast Res. 2005, 5, 859.

7. Uenojo, M.; Pastore, G. M.; Quim. Nova 2007, 30, 388.

8. Zheng, Z.; Shetty, K.; Process Biochem. 2000, 35, 825.

9. Fawole, O. B.; Odunfa, S. A.; Int. Biodeterior. Biodegr. 2003, 52, 223.

10. Bravo, C. E. C.; Carvalho, E. P.; Schwan, R. F.; Gómez, R. J. H. C.; Pilon, L.; Ciênc. Agrotec. 2000, 24, 137.

11. Lonsane, B. K., Ghidyal, N. P., Budiatman, S., Ramakrishna, J.; Enz. Microbiol. Technol. 1985, 7, 285.

12. Correia, R. T. P.; Tese de Doutorado, Universidade Federal do Rio Grande do Norte, Brasil, 2004.

13. Pandey, A.; Ashakumary, L.; Selvakumar, P.; Vuaylakshmi, K. S.; World J. Microbiol. Biotecnol. 1994, 10, 485.

14. Couri, S.; Terzi, S. C.; Pinto, G. A. S.; Freitas, S. P.; Costa, A. C. A.; Process Biochem. 2000, 36, 255.
15. Couri, S.; Tese de Doutorado, Universidade Federal do Rio de Janeiro, Brasil, 1993.

16. Santos, S. F. M.; Nóbrega, J. E.; Pinto, G. A. S.; Silva, F. L. H.; Macedo, G. R.; XV Simpósio Brasileiro de Bioprocessos-SINAFERM, Recife, Brasil, 2005.

17. Rodrigues, M. I.; Iemma, A. F.; Planejamento de experimentos e otimização de processos, $1^{\mathrm{a}}$ ed., Ed. Casa do Pão: Campinas, 2005.

18. Barros Neto, B.; Scarminio, I. S.; Bruns, R. E.; Planejamento e otimização de experimentos, $2^{\mathrm{a}}$ ed., Ed. da Unicamp: Campinas, 1996.

19. Castilho, L. R.; Dissertação de Mestrado, Universidade Federal do Rio de Janeiro, Brasil, 1997.

20. Silva, D.; Martins, E. S.; Silva, R.; Gomes, E.; Bra. J. Microbiol. 2002, 33,318 .

21. www.cnpat.embrapa.br/home/down/index.php?pub/cot_102.pdf, acessada em Outubro 2006. 